\title{
3. エイズに関する検査法の進歩
}

\author{
吉原なみ子 \\ 国立予防衛生研究所エイズ研究センター
}

はじめに

HIV の検査に限らず, 検査は感度が良く, 特異性が 高く, 操作が簡単であり, 短時間に大量処理が可能で あり, しかも安価であることが理想であるが, 残念な がら，これらの条件を満たす検査法は現在見当たらな いので，目的に応じて，その中のいくつかを組み合わ せて検査することになる. HIV の検査はHTLV-Iに 比べて，たくさんのキットが開発されている．現在市 販されているまたは近々市販される予定の HIV-I キットの特徵と問題点を解説し, 次に HIV-II 検査も 簡単に報告する。

\section{HIV-I 抗体検查時の注意点}

キットに用いられている抗原は細胞培養から得られ たウイルス粒子がもっとも多く，その他遺伝子組み換 えによるもの, 合成ペピチド抗原などが利用されつつ あり，その特徵を知って使らことが望ましい．

HIV-I 抗体の検查は最初に ELISA が開発され，そ の後, 次々に他の方法も開発されたが, 初期の ELISA が $1 \%$ 前後の非特異反応があった為，スクリーニング の後, 必ず特異性の高い方法で確認することになって いる. 現在の ELISA の非特異反応は $0.1 \%$ 前後になっ たが確認試験は必要である。たくさんのキットが市販 されているが，わが国ではある基準以上の感度を有す るキットを厚生省が認可している. ELISA キットを使 5場合，1）反応時間の厳守（特に反応時間が短い場 合), 2) 反応温度を正確にすること，3）洗浄をていね いにすることなどの注意が必要である.

PA はわが国でもっとも多く使われている方法であ り, 操作が簡単なキットであるが, 欧米ではなかなか 受け入れられないのは凝集の有無の判定が主観的であ ることも原因であろう。

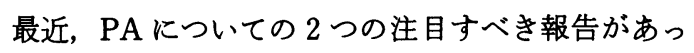
た.

1 つは昨年10月の Lancet に2 例のプロゾーン現象 による疑陰性の報告である。これらの検体は検体を希 釈していくと凝集が強くなり, env抗体過多によるも のであることがわかった，スクリーニング時の凝集像 でも十または+陽性であり, 当然拾うべきであるが慣
れてくると册陽性ばかり注目してしまい，見逃してし まうことがある。

現在のPA env 抗体過多を落としてしまう点は 改良されたが HIV 検查の経験が浅く, 陽性検体に めったに遭遇しないわが国では弱い反応も拾って, 確 認して欲しい.

もら一つは 5 月にシカゴで開かれた AIDS 国際シ ンポジゥムでドィッのDr. DainhardtはPAは ELISA に比べて，疑陽性が多いと報告した。これは多 分, 未感作ゼラチンと比較して少しでも凝集のあるも のを陽性としたためと考えられる。いずれの報告も凝 集法が問題となる点なので使用時判定は特に注意すべ きである.

\section{Karpas 法}

\section{新しい検查法}

最近, わが国で開発した Karpas 法は HIV 抗体の検 查法であり, IFA とほぼ同様な操作である。スライド グラス上に感染細胞と未感染細胞を固定し，希釈した 検体を加えて反応させる，その後酵素標識抗体を反応 させて発色させ, 感染細胞と末感染細胞との発色の差 で判定する. 特殊な器具を使わず, 目視で判定出来る ので便利である. IFA が蛍光顕微鏡で判定するのを Karpas 法は酵素を用いるため, 肉眼で判定できる利 点がある. 判定困難な場合は光学顕微鏡で見るとより 明らかになる。

\section{II. 抗原検查法}

HIV 抗原, 特に p24抗原が測れる ELISA キットが 開発された. HIV 抗原は理論的には感染してから抗体 が検出される前の一時期と感染が進み，p24抗体が消 失した場合に検出されるといわれている．わが国では 抗体が検出される前で HIV 抗原が見つかったという 報告はない.

抗原検索により ARCから AIDSに移行していくと 抗原が検出された症例の報告があり，予後の判断には 有用であろらが，輸血のためのスクリーニングには無 意味である. HIV 抗原検査も非特異反応がみられるた め, 確認試験が必要である.

III. 確認法 (WB とェンブコア・EIA) 
確認法はIFA やWB が一般的であるＩFA は自己 免疫疾患患者血清で非特異反応が見られることがあ る。また，WB は特異性が高いので確認法として最も 信頼されている方法であるが希に偽陽性例が認められ る. 特に p24のみの single band p p24と p55だけの band は注意する必要がある。

憤れていないとband の位置を読み間違えたり，弱 いbandを読み落としたりすることがある。バンドの 濃さも判定基準に加味されるような参照血清が添付さ れていると精度の高い検査となる。

遺伝子操作により env と coreを大腸菌につくら せ, これらの抗原を用いて ELISAを行ら, エンブュ ア, EIA がある。この方法で分子量41000のエンベロー プ蛋白 (env) に対する抗体と gag 遺伝子産物である分 子量24000のコア蛋白 (core) に対する抗体が検出でき る。検体中の抗体を Inhibition の割合で計算する。 ス クリーニング ELISA に比べて，特異性が高まる。

我々の研究室で WB とェンブコア・EIA の比較した ところ様々な組合せができた.WB とェンブコア・EIA は75\%は完全に一致し，90\%はほぼ一致した結果が得 られたが，残り $10 \%$ は判定が出来なかった。このよう な検体は他の方法を試みるか, 追跡する必要があろう. エンブコア・EIA は env 抗体の感度が良く, WB は core 抗体の方が感度が良いと思われた。エンブコア・ EIA は特異性が高いが, GP41と p24のいずれかで判定 することになる.WBは他の band と総合して判断で きる利点がある.

\section{HIV 検查の実際}

HIV 抗体検查をまとめると凝集法 (PA, PHA), ELISA（サンドイッチ法, 競合法), 形態で見る方法

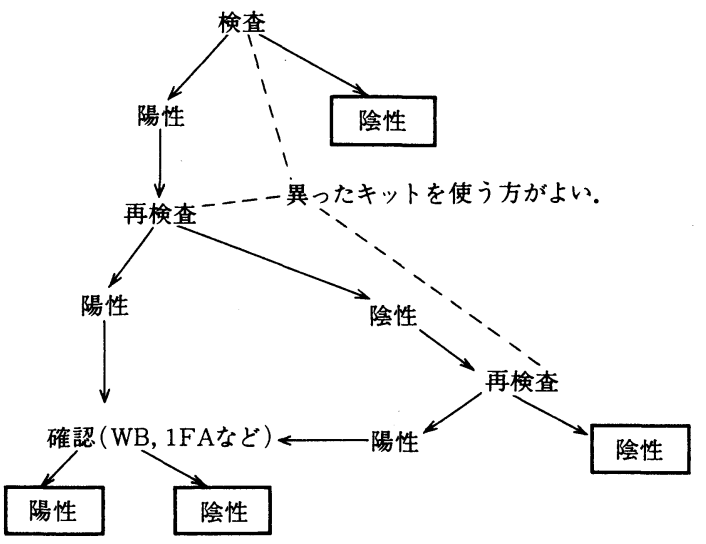

図 1 HIV 検查手順
(IFA，Karpas)，WBなどの抗原の分子サイズに対す る抗体で見る方法（WB， RIP）に分けられる.

HIV 抗体検査は非特異反応があるため, スクリーニ ングをし，陽性ならば再検し，再度陽性ならばIFA や WBなどで確認し判定する(図 1)。スクリーニングで 陽性の場合，異なった方法で再検し，たとえば凝集と ELISA を組み合わせるとか, ELISA ならば他のキッ トで検查すると確認の検体が減らせる，再検時陰性の 場合はなぜ最初陽性になったかを知るためにも，もう 一度検査する位の憤重さが必要である。

判定不能の場合は経過を追って観察する. 判定不能 例を HIV 抗原検査やェンブコア・EIA で確認できた 経験がある。

\section{HIV-II 抗体検查}

HIV-I と II の相違点は特に core 抗体の p24に交差 性があり, env は交差性がない. 京大ウイルス研の速水 教授から HIV-II ウイルスとガーナ人の血清の供与を 受け, ELISA, IFAおよびWBで検討した。

HIV-I の ELISA キットで HIV-II 抗体陽性例の 30 〜 $00 \%$ が陽性となり，HIV-I 陽性例を HIV-II キッ トで測定すると同様に $60 \%$ 近く陽性となった。

したがって，特異的な HIV-II 感染者を決定するに は HIV-I 同様疑陽性を IFA やWB で確認するのは勿 論であるが, HIV-I との cross か否かを見なければな らない. IFA は counter staining として FITC 標識抗 体中にエバンスブルーを加えた。感染細胞と非感染細

表 1 HIV-I 感染例

\begin{tabular}{rr|c|c|c|c}
\hline WB (HIV- I ) & 1 & 2 & 3 & 4 \\
\hline gp160 & + & + & + & + \\
p65 & - & + & + & - \\
p55 & - & + & + & - \\
gp42 & + & + & + & + \\
p31 & + & + & + & + \\
p24 & + & + & - & - \\
& p18 & + & + & - & - \\
& gp140 & - & - & - & - \\
WB HIV.II & & & & \\
& gp104 & - & - & - & - \\
p68 & - & - & + & - \\
& p56 & - & - & - & - \\
p36 & + & + & + & - \\
p26 & + & - & + & - \\
& & & & & \\
IFA & HIV. I & + & + & + & + \\
HIV-II & - & + & - & - \\
\hline
\end{tabular}


表 2 HIV-II感染例

\begin{tabular}{|c|c|c|c|c|}
\hline WE & (HIV-I ) & 1 & 2 & 3 \\
\hline & gp160 & - & - & - \\
\hline & p65 & - & - & + \\
\hline & p55 & + & - & + \\
\hline & $\mathrm{gp} 42$ & $?$ & - & - \\
\hline & $\mathrm{p} 31$ & + & - & + \\
\hline & p24 & + & + & - \\
\hline & p18 & - & - & - \\
\hline \multicolumn{5}{|c|}{ WB HIV-II } \\
\hline & gp140 & - & - & - \\
\hline & gp104 & + & + & + \\
\hline & p68 & + & + & + \\
\hline & p56 & + & - & + \\
\hline & p36 & + & - & - \\
\hline & $\mathrm{p} 26$ & + & + & + \\
\hline \multicolumn{5}{|c|}{ IFA } \\
\hline & HIV-I & + & + & + \\
\hline & HIV-II & + & + & + \\
\hline \multicolumn{5}{|c|}{ ENVACORE } \\
\hline & ENV & - & + & - \\
\hline & CORE & + & + & + \\
\hline PA & (HIV-I ) & + & $?$ & - \\
\hline
\end{tabular}

胞を比較しながら判定した。なお，コントロールの非 感染細胞のMolt4を用いた。

典型例な HIV-I 感染例（表 1), HIV-II 感染例（表 2 ), HIV-I と II の重感染例（表 3 ）を示す.

表 1 はわが国の HIV-I 感染者で HIV-II との cross をみたものでWBで $\mathrm{p} 68,36,26$ にバンドが見られた。 No. 4 の症例のように HIV-I で p24抗体がないものは HIV-II と cross しなかった. HIV-II 感染者は表 2 で 示すようにWB で HIV-I の p65，55，31，24が cross し, IFA は HIV-I で判定不能なものもあった. HIV-I のエンブュアでは core 抗体が全例陽性であり, HIV-I のPA で陽性を示するのもあった。表 3 の重感染例は
表 3 HIV-I と HIV-II重感染例

\begin{tabular}{r|c|c|c|c|c}
\hline WB (HIV. I ) & 1 & 2 & 3 & 4 & 5 \\
\hline gp160 & + & + & + & + & + \\
p65 & + & + & + & + & + \\
p55 & + & + & + & + & + \\
gp42 & + & + & + & + & + \\
p31 & + & + & + & + & + \\
p24 & + & + & + & + & + \\
p18 & + & + & + & + & - \\
gp140 & + & + & + & + & + \\
gp104 & + & + & + & + & + \\
p68 & + & - & + & + & + \\
p56 & + & $?$ & + & + & + \\
WB (HIV-II) & & & & & \\
& + & $?$ & + & + & + \\
p26 & + & + & + & + & + \\
& & & & & \\
IFA & & + & + & + & - \\
HIV. I & + & + & + \\
HIV-II & + & + & + & + & + \\
\hline
\end{tabular}

HIV-I の WB で env と core が陽性であり, IFA でも 両方が光っていた。

HIV-II の検査は HIV-I と core の部分が crossする ため，ELISA およびIFA だけでは完全に区別できな い.WBでは env 抗体の gp140, gp105だけが特異的で あるがバンドが非常に見にくく慎重な判定が必要であ る. 輸血の分野で HIV-II の検査が必要となった場合, HIV-I と II の 2 つの検査をすることは大変であるし, どちらの感染かを区別する必要もない。

HIV-I と II は core が cross しているけれども core 抗体がない感染者もある。したがって, core 部分だけ に頼るわけもいかないので, 現在の HIV-I 検査に HIV-II の env を加えて, HIV-I と II の両方を検出で きるキットの開発が望まれる。 